\section{Criptococosis gástrica en paciente VIH}

\section{Gastroduodenal cryptococcosis in an AIDS patient}

\section{Sr. Editor:}

La criptococosis en pacientes con infección por el virus de la inmunodeficiencia humana (VIH) cursa generalmente como una meningitis criptocócica ${ }^{1}$, sin embargo, la localización gastroduodenal es muy rara ${ }^{2}$. Presentamos un caso de criptococosis diseminada con afectación gástrica, que debutó con sintomatología digestiva.

Comunicamos el caso de un varón de 46 años que consultó por cuadro constitucional de varios meses de evolución, con disfagia y epigastralgia, sin fiebre. Tenía antecedentes de etilismo y consumo de drogas por vía parenteral; no se conocía VIH. En el examen físico destacaban una delgadez patológica, candidiasis oral y hepatoesplenomegalia. Exámenes de laboratorio: leucocitos 3,4 x $10^{3} \mathrm{dl}, \mathrm{Hb} 8,8 \mathrm{~g} / \mathrm{dl}$; plaquetas $225 \times 10^{3} \mathrm{dl}$; AST 151 UI/l , ALT 521UI/l, GGT 229 UI/l. Radiografía de tórax normal. Se practicó una tomografía axial computarizada torácica-abdominal, que informó una hepato-esplenomegalia y engrosamiento del cuerpo gástrico. Se realizó gastroscopía que mostró a nivel del antro una mucosa gástrica con signos de gastritis crónica y un punteado blanquecino que llegaba hasta el duodeno; se practicaron biopsias. Se recibieron resultados positivos en sangre para VIH y el antígeno criptocócico (títu- los de 1/1.280), por lo que se realizó una punción lumbar que mostró un líquido cefalorraquídeo (LCR) claro, con cito-bioquímica normal y antígeno criptocócico positivo (títulos 1/2.000). La biopsia gástrica mostró la presencia en la zona luminal de la mucosa de detritus con formaciones redondeadas PAS positivas de 4-7 micras, compatibles con criptococos (Figura 1). En el cultivo del LCR hubo desarrollo de Cryptococcus neoformans. Los CD4 fueron de $54 \mathrm{~mm}^{3}$. Se inició tratamiento con anfotericina B liposomal ( $4 \mathrm{mg} / \mathrm{kg} /$ día), pero el paciente falleció a las dos semanas.

La infección criptocócica en pacientes VIH, además del sistema nervioso central (SNC), se puede localizar en pulmón, tracto urinario, hígado y piel $^{1}$. La localización gastrointestinal es excepcional, especialmente como forma de aparición de la criptococosis; solo hemos encontrado ocho casos descritos en la literatura ${ }^{2-6}$.

La criptococosis gastroduodenal se puede manifestar como un compromiso general, con predominio de la sintomatología digestiva: dolor abdominal, disfagia, náuseas y vómitos ${ }^{4,6}$, como ocurrió en nuestro caso, o con síntomas gastrointestinales en pacientes con una meningitis criptocócica. Las imágenes endoscópicas descritas son: nódulos, pólipos inflamatorios, placas blanquecinas y úlceras ${ }^{2}$. En ocasiones, la criptococosis gastroduodenal es la primera manifestación clínica de la criptococosis diseminada y su hallazgo obliga a la realización de una punción lumbar, para descartar una afectación meníngea.

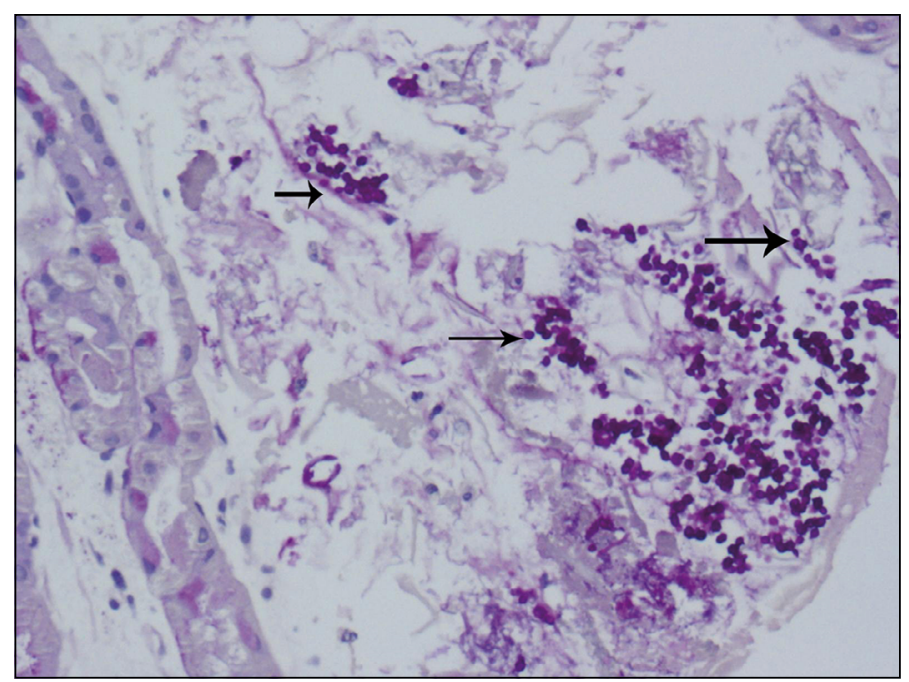

Figura 1. Presencia en la zona luminal de la mucosa gástrica de detritus con formaciones redondeadas PAS positivas, de 4-7 micras, compatibles con criptococos. 
En la literatura española sólo hay un caso de un paciente con afectación gástrica, que debutó con sintomatología digestiva y la endoscopia mostró un lesión ulcerada en el estómago; tuvo mala evolución, a pesar del tratamiento antifúngico ${ }^{4}$.

Se ha descrito un caso de localización yeyunal que debutó como un abdomen agudo, sin documentarse otra localización, que respondió al tratamiento quirúrgico y posteriormente se agregó anfotericina $\mathrm{B}^{5}$.

La evolución de nuestro paciente fue desfavorable a pesar del tratamiento antifúngico, al igual que la mayoría de los casos descritos previamente, probablemente por el grave deterioro inmunológico de los pacientes.

Como conclusión, la infección criptocócica puede manifestarse en pacientes VIH con sintomatología digestiva. La endoscopia, con estudio histológico, pueden certificar el diagnóstico.

\section{Pablo Roig-Rico ${ }^{1}$ Elisabet Delgado-Sánchez ${ }^{1}$, Dulce Marín-Tordera ${ }^{2, a}, M^{a}$ Teresa Chulia-Gómez ${ }^{3}, M^{a}$ José Mayol-Belda ${ }^{3}$, Antonio Martínez-Egea ${ }^{4}$ ${ }^{1}$ Servicio de Medicina Interna. Hospital San Juan de Alicante. ${ }^{2}$ Hospital General de Alicante. ${ }^{3}$ Servicio de Anatomía Patológica, Hospital San Juan de Alicante. ${ }^{4}$ Sección de Digestivo, Hospital San Juan de Alicante. Alicante, España. ${ }^{a}$ Matrona.}

\section{Referencias}

1. Chuck SL, Sande MA. Infections with Cryptococcus neoformans in the acquired immunodeficiency syndrome. N Engl J Med 1989; 12: 794-9.

2. Chalsani N, Wilson CM, Hunter HT, Schwartz DA. Endoscopic features of gastroduodenal cryptococcosis in AIDS. Gastrointest Endosc 1997; 45: 315-7.

3. Washington K, Gottfried MR, Wilson ML. Gastrointestinal cryptococcosis. Mod Pathol 1991 ;4: 707-11.

4. De Otero J, Flor A, Cortés Cuenca A, De Torres I, Capdevilla JA. Ulceraciones gastrointestinales criptococócicas en un paciente HIV-positivo. Enferm Infecc Microbiol Clin 1994; 12: 176-7.

5. Saha S, Agarwal N, Srivastava A, Kumar A. Perforation peritonitis due to gastrointestinal cryptococcosis as an initial presentation in an AIDS patient. Singapore Med J 2008; 49: e305-7.

6. Girardin M, Greloz V, Hadengue A. Cryptococcal gastroduodenitis: a rare location of the disease. Clin Gastroenterol Hepatol 2010; 8: e28-9.

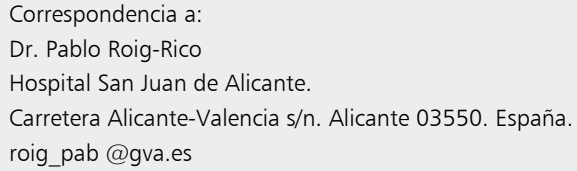

